\title{
Zoocentrism in the weeds? Cultivating plant models for cognitive yield
}

\author{
Adam Linson $^{1}$ (iD $\cdot$ Paco Calvo ${ }^{2}$
}

Received: 4 May 2020 / Accepted: 28 August 2020 / Published online: 5 September 2020

(c) The Author(s) 2020

\begin{abstract}
It remains at best controversial to claim, non-figuratively, that plants are cognitive agents. At the same time, it is taken as trivially true that many (if not all) animals are cognitive agents, arguably through an implicit or explicit appeal to natural science. Yet, any given definition of cognition implicates at least some further processes, such as perception, action, memory, and learning, which must be observed either behaviorally, psychologically, neuronally, or otherwise physiologically. Crucially, however, for such observations to be intelligible, they must be counted as evidence for some model. These models in turn point to homologies of physiology and behavior that facilitate the attribution of cognition to some non-human animals. But, if one is dealing with a model of animal cognition, it is tautological that only animals can provide evidence, and absurd to claim that plants can. The more substantive claim that, given a general model of cognition, only animals but not plants can provide evidence, must be evaluated on its merits. As evidence mounts that plants meet established criteria of cognition, from physiology to behavior, they continue to be denied entry into the cognitive club. We trace this exclusionary tendency back to Aristotle, and attempt to counter it by drawing on the philosophy of modelling and a range of findings from plant science. Our argument illustrates how a difference in degree between plant and animals is typically mistaken for a difference in kind.
\end{abstract}

Keywords Homology · Homoplasy · Model organisms · Cognitive modelling · Minimal cognition · Aristotle

Adam Linson

adam.linson@stir.ac.uk

1 University of Stirling, Stirling, UK

2 Universidad de Murcia, Murcia, Spain 


\section{Introduction: What's in a kingdom name?}

Biological taxonomy is anything but straightforward. While there is an obvious relationship between the branches of the 'tree of life' and lines of direct genetic descent, there are further complexities in play when it comes to sub-dividing creatures into different species and even kingdoms (Whittaker 1969). Branches are defined differently depending on criteria ranging from operational considerations to various forms of ontological classification by natural kind (Bird 2018).

There is also a subtle but enduring historical influence that contributes to how scientists and philosophers regard relationships between taxonomy and homology (Griffiths 2007; Hall 2003; Scotland 2010). The construal of these relationships is especially relevant for cognitive phenomena. Specifically, taxonomic considerations influence how behavioral homologies are understood, where the latter are tied to such processes as perception, action, memory, and learning (Ereshefsky 2007a).

However, due to how physiology diverges in speciation, there is a strong normative component to whether any form of an organism's environmental sensing qualifies as perception, or directed movement as action, or demonstrated recall as memory, and so on. Crucially, how these notions are defined and modelled theoretically influences their empirical investigation. Even though the initiating concepts and models are typically revised over decades of research, this is not solely due to an accumulation of evidence.

Consider that in the lead-up to the Chemical Revolution, competing sets of experimental evidence were tied to which of two theoretical constructs were accepted, phlogiston or caloric (Chang 2010). Similarly, in the lead-up to relativity theory, physicists provided evidence for fields in fundamentally different ways, depending on whether the construct of material aether was accepted or rejected (Nersessian 1984). In short, even when evidence confirms the theoretical foundations of a scientific investigation, this does not amount to establishing an ahistorical truth. Moreover, once a theory has become scientifically secure, history has shown that recalcitrant evidence can be dismissed repeatedly.

It is in this light that we consider plant cognition (in the general sense indicated above). Cognition has long been thought of as the exclusive province of animals. Those who insist otherwise may be dismissed as old-fashioned animists, or perhaps more charitably, as using poetic license and trafficking in metaphors. In fact, there is a substantial body of rigorous scientific evidence which shows that what is widely regarded as animal cognition is also found in plants, down to its physiological and behavioral basis. We suggest here that at least one reason the preponderance of evidence is largely disregarded, downplayed, or outright ignored is due to the conserved momentum of ancient history.

\section{Overview}

Aristotle has had an overt and lasting influence throughout the history of philosophy and science. The animal/plant distinction, while scientifically entrenched and 
seemingly intuitive, in part can be traced back to his distinction between organisms with self-motion (locomotive species) and those without (sessile species). The influence of this ancient baggage can be felt even in otherwise radical recent projects, such as making the case for attributing consciousness to non-humans, with the notable exception of plants-precisely because they lack the "capacity for endogenous locomotion" (Reber 2016; cf. Calvo 2018).

Significantly, not only does Aristotle treat locomotion as a marker of cognitive agency, thereby excluding plants (Gill 1994), he also regards plants as devoid of perception. ${ }^{1}$ As Freeland (1992) has noted of the sensation of touch, for Aristotle,

it is the most basic of all the senses, the only one common to all animals. Certain primitive animals [according to his account], such as sponges and ascidians, possess touch alone of all the senses, and this is enough to distinguish them from the plants which they otherwise closely resemble. [...] He also sees [touch] even in primitive animals as providing a basis for certain higher-order cognitive capacities. ${ }^{2}$ (Freeland 1992)

In what follows, we present a critique of the Aristotelian and arguably derivative current approaches to distinguishing plants from animals. Our specific concern is the circularity of narrowly defining a relevant process (locomotion or perception) to limit the set of organisms that exhibit it, and then proclaiming that one only finds capacities that depend on the relevant process (cognition) in those organisms. We aim to show that this issue itself revolves around modelling.

While the assumed cognitive distinction between humans and non-human animals remained in force for millennia, for many, this now has come to be regarded as a difference in degree rather than kind. With the current sophistication in modelling and experimental research on plants, the time is ripe to get plants admitted into the cognitive club. We argue that resistance to this idea is in part because animals and plants remain historically reified presumptive natural kinds on opposite sides of the cognitive boundary. To put our thesis in perspective, we draw on sources spanning from classical antiquity-where natural science and philosophy were more or less unified-to contemporary scholarship, where specialized investigations in both science and philosophy have critically complemented one another.

The argument we advance here is in general agreement with Allen (2017), who welcomes the fact that

cognitive scientists are increasingly applying their models and analyses to systems above and below the level of a prototypical, multicellular animal with a brain, spanning unicellular organisms and systems with just a few hundred

\footnotetext{
1 We defer to classics scholars to ground the plausibility of our readings throughout, without delving into the myriad internal contradictions and competing interpretations of ancient texts. For such a nuanced treatment of Aristotle on animal locomotion, see Gill (1994).

${ }^{2}$ Here and throughout, for readability, we omit in-line references to the works of Aristotle in citations of other authors; textually relevant details are footnoted. In this passage, the original citations are from $D e$ Anima (DA), History of Animals (HA), and Parts of Animals (PA).
} 
neurons below, and to the collective action of colonies or groups of organisms above. (Allen 2017)

He contextualizes this inclusive position in relation to the broad (but not unanimous) commitment among philosophers to an overly conservative, historically favored notion of cognition. Our sympathetic argument, apart from focusing specifically on plants, also takes a rather different general approach. Namely, whereas Allen's approach centers on conceptual definitions of cognition, ours centers on models of cognition. In this context, we treat models as epistemic tools (Knuuttila 2011), which means they are artifacts that are designed, constructed, and manipulated to facilitate scientific inquiry.

We argue that, for any arbitrary model of cognition that is not bound to humans alone a priori (e.g. by requiring language for cognition), careful theorizing and consideration of scientific evidence will show that plants meet the criteria for cognition established by the model. Perhaps counterintuitively, this entails that we argue against anthropormorphizing plants, and more generally, against zoocentric explanations. In the next section, we situate our position in related work; in the third section our focus turns to models; the fourth and fifth sections are concerned with Aristotle, kinds, and homologies; the sixth and seventh sections delve more deeply into plant science; followed by the concluding section.

\section{Not quite out on a limb: related work}

Broadly, we follow the contours here of what philosophical and cognitive theories of embodiment and interactive environmental engagement brought about, in pushing the boundary of cognition to yield to non-human animals (e.g. Clark 1997; Lakoff and Johnson 1999; Wheeler 2005). Our emphasis on bodies and their relationship to a niche is also shared with Gibsonian ecological psychology. The view we elaborate has the aforementioned elements and perhaps others in common with Thompson (2007) and Varela et al. (1991), but we adhere only to concepts found in standard biology and the philosophy (and scientific application) of modelling. Similarly, our view shares an emphasis on the role of generalizability in cognitive modelling, found in Chemero's (2009) linking of ecological psychology with dynamical systems theory.

The orientation of the latter three approaches concerns antirepresentationalism in cognitive science, which lies beyond the present scope. There is, however, a substantive point of divergence we have from the following claim: "it is important to distinguish between nonlinear dynamic systems as abstract mathematical models and as observable biophysical systems" (Thompson 2007, p. 430). Our position is not that this distinction should be collapsed. Rather, it is that the only meaningful sense in which an observable biophysical system could be counted as a nonlinear dynamic system is in virtue of an appeal to an abstract mathematical model. Such a model would be required to interpret observable evidence as evidence for the system in question. Normative considerations would support the model definition and also 
inform the determination of how well the evidence supports the use of the model for a particular aim. (This point is elaborated in the next section.)

Although there have been a variety of takes on the relationship between adaptation and cognition (see Thompson 2007), our relatively deflationist view on the two is simply that adaptive processes can involve any processes relating to achieving organism-niche dynamic equilibrium, some but not necessarily all of which may be cognitive. In most fields, whatever might be called cognitive processes will exhibit a core dependency on a number of constitutive processes, namely, some version of environmental sensing (perceiving) and real-time or time-delayed perceptioninformed action. The temporal component typically implicates related processes of memory and learning in various forms.

Under this broad umbrella of cognition, our specific focus is on correlated physiology and behaviors which underpin lifespan (and species) environmentally interactive processes that are parallel in plants and animals. We use a non-technical sense of parallel that may turn out to relate to one or more forms of deep homology (Scotland 2010), or possibly homoplasy in the sense of Lankester (1870), as has been plausibly suggested (Baluška and Mancuso 2009). We note, however, that even 'mere' analogy, as Darwin once put it (Hall 2003), would suffice for the present argument. Nevertheless, with respect to deep homology, it bears mentioning that there are plant homologues of mammalian proteins that support biophysically equivalent adaptive physiological mechanisms - and whose genetic profiles indicate common evolutionary ancestry (Keller et al. 1998).

Using an analysis of evolutionary convergence, Keijzer (2017) mounts a systematic defense of the claim that "plants easily fulfil the requirements" for biologically embodied cognition. As Keijzer (2019) later suggests, it appears to be due to traditionally animal-centric, if not strictly human-centric, psychological concepts such as 'decision-making' that "claims concerning plant behavior may sound weird or simply wrong, despite the evidence supporting such statements".

Decision-making is particularly important to the sense of cognition relevant here. This is because we do not adopt the standard dichotomy of cognitive 'information processing' and purely dynamical agent-environment interactions (Chemero 2009). Nor, however, do we adopt what might be called the classical cognitive information processing scheme (sometimes known as the computational theory of mind), which leads Burge (2010) to distinguish sensory registration from perception proper, in contrast to the present treatment. The classical scheme, also relevant below, is one that locates computational cognitive models in the mind of the organism. An example of this would be computing the distance between objects in three-dimensional space from a two-dimensional projection. The cognitive models that we refer to, however, are not held to be in the mind of the cognizer. Rather, they are descriptive theoretical models for scientific inquiry into cognition. In this sense, they are no different than population models, which do not entail that a population computes anything, even when computational models are used to describe it.

Using this latter sort of computational approach, Linson et al. (2018) make a case for a generalized account of cognition. This generalization in part builds on the same modelling approach applied specifically to plants (Calvo and Friston 2017). (We address models further in the next section.) These and other related work (including 
the above references on embodied cognition) are part of a growing body of mutually supportive research that pushes back against restricted understandings of notions such as cognition, intelligence, and even consciousness, regarding lifeforms including (but not limited to) plants (e.g. Baluška and Levin 2016; Baluška and Reber 2019; Calvo Garzón and Keijzer 2009, 2011; Calvo 2017; Calvo et al. 2017, 2020; Corcoran et al. 2020; Karban 2008; Kirchhoff et al. 2018; Marder 2012; Margulis 2001; Ramstead et al. 2018; Trewavas 2002, 2003, 2014).

\section{The garage doors of cognition}

Dissenters to such expanded boundaries remain more prominent. To take a recent example of the conservative position, Adams (2018) grants that non-human animals can be genuinely cognitive, while still opposing this attribution to plants. The objection seems to be at least in part due to a classical perspective on cognitive information processing. This traditional standpoint views simple systems such as electronic garage door openers as adequate models of elementary biological computation that fall short of 'real' cognition. With this example in mind, Adams (2018) suggests that giving animal-like status to (e.g.) decision-making of the sort exhibited by plants is akin to applying the Dennettian intentional stance to an electronic garage door opener.

Consider, however, that the intentional stance is concerned with beliefs. Specifically, for Dennett, it implies that there is no special 'hard' threshold between ascribed 'as if' beliefs and 'real' beliefs (Dennett 2009). Therefore, according to the above critique, plant (and garage door opener) cognition must be 'as if' cognition, animal cognition must be 'real', and proponents of plant cognition must be advocating no difference between 'as if' and 'real' cognition. This, however, is a false conclusion, once it is understood how accounts of cognition are grounded in modelling.

Notice that Dennett would agree that humans, animals, plants (and garage door openers) could be said to have beliefs, without necessarily being cognitive:

even when intentional glosses on (e.g.) tree-activities are of vanishingly small heuristic value, it seems to me wiser to grant that such a tree is a very degenerate, uninteresting, negligible intentional system than to attempt to draw a line above which intentional interpretations are 'objectively true'. (Dennett 1976, p. 180)

But, if Dennett's intentional stance methodology requires that beliefs be treated as part of a behavioral modelling exercise, then beliefs can be modelled as having been formed at least in part through perception, memory, learning, and so on. Decisionmaking can be added to the model as acting on beliefs. It is perfectly consistent to say that there are empirically identifiable processes of perception, action, memory, and learning that are best understood through models of cognition that include belief attributions, where beliefs are the only element that is equally 'as if' and 'real'. From this perspective, the question concerning what constitutes 'real' cognition shifts to how its constitutive processes are physically implemented. 
In this respect of implementation, we are in agreement with Sloman (1988) that the 'design stance' must be the arbiter of whether and how extrinsic behavior emerges from intrinsic capacity. That is to say that the components within the organismic boundary must be organized in a particular way (a 'design') for 'real' cognition or its constitutive processes such as memory to emerge. By this measure, a garage door opener does not 'remember' if the door is open or closed based on a persistent internal state within an electronic circuit, yet it behaves as if it does (the bare encapsulation of a past state is not the character of memory that is of interest, as we explain below). However, according to controlled experiments, using models in part based on invertebrate and vertebrate neurons, even unicellular organisms can remember their spatial trajectories (Kunita et al. 2016). This latter simple form of memory at least constitutes a better scientific model of complex human memory than a garage door opener. From the design stance, simplicity does not adjudicate between 'as if' and 'real' cognition; either can be simple or complex.

One variety of simple biological models, known as model organisms, is often used to investigate target phenomena through the use of homologies. (We expand on this point in the next section.) As Kaplan (2017) points out, neuroscientists began to investigate the critical role of long-term potentiation (LTP) in memory based on rodents and rabbits, and later in macaques, to establish its role in human memory. Further research then showed the same mechanism was also present outside of mammals, in sea slugs. More recently, molecular and other subcellular aspects of LTP have been identified that appear to subserve memory not only in animals, but also (homologously) in plants, although more research is needed (Michmizos and Hilioti 2019).

What is important to the present discussion is how the meaningful character of a cognitively constitutive process (e.g. memory) is maintained in inquiry. For example, if memory is characterized as being reflected in the ability to read out an encapsulated past state, then not only would humans and garage door openers be adequate subjects of an inquiry into memory, but so would a 'memory foam' cushion. This is obviously inadequate. Crucially, however, an inquiry on biological memory could still use a synthetic stand-in or computer simulation in place of a living being. The point is that there is something specific of interest about the target cognitive phenomenon that is reflected in biological exemplars, which may be studied in various ways.

\section{Currents, models, and current models: philosophy, theory, and practice}

The claim that animals, but not plants, can have "internal states that mean (in the sense of have truth values) things outside the system", or "that are possibly false in what they represent", or "that have as part of their meaning a non-existent future state of affairs" (Adams 2018) is to miss that these are features of an animal model of cognition that was once regarded as a strictly human model. When further research on animals revealed that their cognitive processes could be modelled in a manner equivalent to humans (see Allen and Bekoff 1999), what was previously a 
rigid boundary was replaced by a point on a complexity continuum. (It is not widely disputed that humans exhibit more complex cognition than other animals.)

Crucially, it is a model of human cognition that tells us, for example, that behavioral and/or linguistic evidence indicates to an observer that a subject holds a belief Q, even if the model remains implicit in such usage. Additional psychological, neuronal or other physiological evidence could indicate that a subject holds a belief Q, using a variety of methodological strategies that may reveal a controlled formation or disruption of the belief, for instance, depending on the model. When new technologies of observation and methodological procedures are established, it may transpire that an existing model can accommodate new evidence. For example, where one once might have said, "it must be 'as if' there is weather on Mars", it is now accepted that there is 'real' weather on Mars, by appealing to Earth-derived numerical models constrained by newly available observational data (Leovy 2001). In a related sense, there is no need to appeal to 'as if' cognition or other anthropomorphisms to undertake a cognitive ethology of animals, plants, and earlier lifeforms, when drawing on observations. There is, however, a need to appeal to models.

Many organisms may be counted as cognitive analogues, not necessarily in an evolutionary sense (see Kaplan 2017), but in the sense of being "concrete" models (Weisberg 2013). This describes models that are (or could be) physically instantiated, like model cells or organisms. Concrete models are used in contemporary science to understand a broader class of phenomena found in other physical instantiations. For example, a generic eukaryotic cell may be used as a model of how certain organelles or membranes behave generally, or a mouse may be used to understand human neurophysiology.

Two (or possibly three) aspects of concrete modelling are of interest here. The first pertains to empirically linked homologies, such as those which demonstrate that mouse and human brains are evolutionarily continuous. This known continuity certainly contributes to the use of mice as model organisms for humans. However, even if such a continuity were empirically disproved, a second aspect could also support the use of a model organism; namely, a demonstrated equivalence to the target with respect to the model's role in practice. For instance, a completely synthetic mouse-like creature designed to exhibit the same observable responses to pharmacological agents as humans could turn out to be empirically robust as a model organism.

When more abstract attributions are considered, such as a "defensive response", this is closely related to the second aspect, but could be regarded as a third. For example, it is one thing to say that a synthetic mouse runs to or from a cat upon the ingestion of a certain drug, but it is quite another to call this a modulation of its defensive response. Here, the matter pertains to the target as much as the model: what constitutes a defensive response? That this is a normative matter rather than a perspective-free one can be made clear if the question is restated: using what model under what methodological conditions should an observation be counted as evidence of a defensive response? (This is meant only as an illustration; however, it seems most if not all organismic defensive responses entail cognitive processes as we define them.) 


\section{Neutral or normative?}

The normative matters play out in such cases in the decisions on what constitutes the observable processes and their interrelationship. If models of defensive behavior account for perceiving and discriminating a threat and acting responsively, or models of memory account for perceiving and subsequently demonstrating recall, then the constitutive components are as important as the target phenomenon. On this basis, without any invocation of anthropomorphism, it is justifiable to grant that even unicellular eukaryotes and protists are perceivers, in so far as they exhibit a defensive repertoire and memory defined in the preceding way. These attributions are justified using models and observations of the constitutive and integrated capacities provided by controlled experiments on cellular mechanics, biochemistry, and behavior (Dexter et al. 2019; Kunita et al. 2016). Once it is granted that modelling and experimental evidence can demonstrate how behavior emerges from physiological underpinnings in a similar manner across species or kingdoms, many imagined dividing lines fade in significance.

Our view shares much in common with the earlier incarnations of the life-mind continuity thesis (Godfrey-Smith 1994; Wheeler 1997), but our central argument is not that life is proto-cognitive. The more indirect affinity we have with those views comes from a level of generality centered on the whole organism at which lines are blurred between life, adaptation, and cognition. At this level of generality, a nonexhaustive characterization of fundamentals for modelling biological, adaptive, cognitive systems can be given as follows:

(i) An organism-niche boundary (even if ultimately transitory over longer timescales),

(ii) A set of organismic mechanisms implicated in processes for niche-perceiving and niche-acting-upon that subserve gaining fuel and avoiding harm (even if ultimately transitory in development), and

(iii) Mediation of the processes in (ii) by endogenous electrical activity.

This list is deliberately broad enough to encompass competing mainstream viewpoints, including purely process ontologies (Nicholson and Dupre 2018). Notice that, even upon close scrutiny, no intrinsic distinction between plants and animals follows from (i) through (iii). Yet, this distinction, mirroring the classifications of Plantae and Animalia, remains forcefully operative. To maintain the distinction, one can point to various differential factors, such as cell types. But, ultimately, even cell types are implicated in physiological processes that support behavioral capacities.

From this perspective, cell biology and locomotion-the latter regarded as a principal plant/animal dividing line (we will get to brains later on) - are fundamentally interrelated. Although locomotion may appear as a neutral criterion, it is normatively privileged over other organismic strategies that accomplish similar ends. For instance, locomotion plays a role in defensive and foraging behaviors, and yet these behaviors are also identified in non-locomoting organisms. At the physiological level, the cellular mechanics and biochemistry of animal muscle action and the directed, coordinated contraction and expansion action of plants are based on 
near-identical molecular and mechanically similar subcellular processes (Gorshkova et al. 2018; Simons 1992). Proprioceptive sensing for bodily self-positioning is found in plants as well as animals (Bastien et al. 2013). As suggested above with the generalizable subcellular basis of memory, in a similar manner, locomotion could be modelled as a special case of the general capacity for directed spatial traversal. Instead, more frequently, locomoting organisms-i.e. animals, but not plants-are treated as an essential kind, which brings us back to Aristotle.

\section{Ancient roots: rise of the walled Kingdoms}

Among classics scholars, there is a broad consensus that Aristotle-founder of zoology, among other contributions- had an idiosyncratic reading of his forerunner Parmenides (see e.g. Loux 1992). An alternative reading of Parmenides was offered by Aristotle's student, Theophrastus, known as the founder of botany. The latter's take on Parmenidean naturalism can be summed up succinctly: sense perception and further cognition of the world is attained by beings through their internal activity of light or heat (Bredlow 2011). Looking back to the ancient world, we note that it is neither anachronistic nor audacious to read 'internal activity of light or heat' as being related to endogenous electrical energy. ${ }^{3}$ (This will take on added significance in the section after next, "Getting nervous: the electrophysiology of plants".)

While Theophrastus offered insight into the systematic ecology of plants and animals as co-equals engaged in parallel organism-niche dynamics (Hughes 1985), it was of course the Aristotelian hierarchical animal/plant dichotomy that took hold. This is epitomized in early modernity by Linnaeus's systematic botany and zoology, which continues to undergird contemporary biology and cognitive science (Kutschera and Briggs 2009). Ironically, the highly influential Linnaean taxonomy, and its direct predecessor, that of John Ray, were derived from theories of 'generative' (reproductive) descent based on research into plant species (Wilkins 2009). Despite this derivation, in most of the biological literature, plant/animal parallels are scarcely if ever considered, with notable exceptions that we draw on here. In particular, the alternative perspective Theophrastus offered is echoed by none other than Darwin, albeit in his largely overlooked writings on plants, which we refer to below.

There is some controversy surrounding interpretations of the Aristotelian approach, especially regarding questions of species essentialism (Lennox 2005, 2009; Stein 2018; Winsor 2003). We will clarify a narrow aspect of this, while sidestepping the central debates about species that seem to rage on in philosophy of

\footnotetext{
${ }^{3}$ Before Parmenides, a limited understanding of the natural phenomenon of electrical energy was already grasped by Thales of Miletus (c. 624-546 BCE), who essentially coined (repurposed) the term 'electron', meaning amber. This was based on static electrical phenomena of deliberately caused amber friction, in other words, basic experimental physics of electromagnetism. Subsequently, Aristotle and Theophrastus were aware of the electrical discharge of the torpedo ray, including aspects of its transmissibility through a medium and human physiological electric shock effects. See e.g. Green and Hazard (1809); see also Finger and Piccolino (2011), pp. 36ff. Moreover, according to the comprehensive analysis of Theophrastus on Parmenides by Bredlow (2011), our claim could be pushed further still: it appears to be an ancient theory of the relationship between environmental and organismic energetic excitation that is remarkably consistent with contemporary biophysical accounts.
} 
biology (Zachos 2016), such as whether species should be construed as individuals (Ereshefsky 2007b), as synchronic or diachronic entities (Stamos 2002), and other related distinctions. More directly related to the present context, Griffiths (1994) discusses species, clades, and philosophical kindhood, but with a stronger emphasis on common ancestry than we require here. Also of note, Ereshefsky and Reydon (2015) offer a detailed account of kinds in relation to species, with a dedicated focus on epistemology. ${ }^{4}$ In contrast to these analyses, our primary concern is with models of cognition, rather than conceptions of species (although we suggest how the latter can have implications for the former).

The closest account to our own is not focused on cognition, but rather on Aristotle's conception of human rationality (Boyle 2017). Boyle notes that the Aristotelian difference in kind is reflected "not merely by a trait" possession, but by "a characteristic whose presence transforms what it is to be" that kind of creature (Boyle 2017, p. 114). This shows that Aristotle is not concerned with isolable capacities that add further powers to an existing stock, but rather, with "a global transformation of the kind of living being that bears [these] capacities" (Boyle 2017, p. 116). Perhaps surprisingly, this speaks to our core argument about modelling, in that it suggests that the model one would need to adequately reflect (e.g.) language use would exhibit a qualitative difference from simpler proto-language models. ${ }^{5}$

Given Aristotle's historically constrained insufficient technical apparatus, he could not avoid overlooking significant aspects of plants. He thus presumed that locomotion and perception were evidence of a fundamental kind transformation from plants to animals (whereas his human story seems largely to have turned out to be right). Unfortunately, however, his inadequate a posteriori analysis has become an a priori premise of contemporary accounts of cognition, mediated by a later taxonomic kingdom division.

Below, we examine how taxa (as reflective of kinds) influence models that can either reveal or obscure homologies. This emphasis requires us to examine a specific issue that arises in Aristotelian inquiry. More generally, setting aside the exclusion of plants, the below account remains compatible with Wheeler's understanding of Aristotle as a viable foundation for biological cognitive science (Wheeler 1997).

\section{Some are more equal than others}

Following Lennox (2005), it can be said that Aristotle's approach to sub-dividing (effectively natural) kinds was to proceed by finding clusters of co-extensive features that include capacities and morphological traits, before moving on to infer causal and/or functional explanations. In this context, high-level groupings such as 'legged' creatures provide only a provisional, preliminary attempt at sub-division. In the process of inquiry, these initial divisions are almost immediately supplanted by

\footnotetext{
${ }^{4}$ The level of generality that suffices here roughly relates to the cases they describe in which 'ordinary kinds' correspond to 'scientific kinds', as we believe to be historically the case with plants and animals.

${ }^{5}$ For a more detailed example, Corcoran et al. (2020) examine how the transformative cognitive capacity of counterfactual evaluation by organisms can be reflected by the addition of hierarchical levels to a computational model.
} 
further sub-division (in this case, into bipeds, quadrupeds, etc.). This process eventually concludes with what are regarded as epistemically valuable indivisible groups, deemed worthy of playing a role in later stages of inquiry (Boyle 2017; Stein 2018).

Thus, when Aristotle identifies as common to all living beings-plants, animals, and humans - such properties as growth, decay, and transformative development, it is clear then that this comprises an early entry point into his sub-dividing venture. (A categorization of this breadth, however, is not as disposable for Theophrastus, in so far as it would be co-extensive with the class of beings with 'internal activity of light or heat'.) Following the living/non-living division, Aristotle cleaves apart the class of living things into a further dichotomy, with plants on one side, animals on the other, retaining humans as a special case of animals. As described above, Aristotle views plants as the only subset of living beings that lack perception and selfmotion, in addition to lacking the related property of rationality.

Already at the outset of this Aristotelian naturalist enterprise, plants are excluded from further animal sub-divisions, for instance, those that distinguish modes of locomotion (terrestrial, aerial, aquatic) and related capacities (e.g. hunting and foraging). These and other features contribute to what Aristotle regards as different 'modes of life' (bios) that bear on correlations with morphological features: being aerial and having wings; being a winged predator and having a curved beak (Lennox 2005; see also Lennox 2009). If the first grouping picks out birds, the second supports a continuity relation in a similarity space among 'forms' of bird mouths, for instance, between curved beaks and the flat bills of some non-predatory birds.

Through this enumeration process, Aristotle also aims to discover discontinuous analogues (e.g. bird:wing :: fish:fin). These initial correlated observations then support subsequent analyses that produce properly causal/functional epistemic claims: animals (birds, fish) have appendages (wings, fins) to locomote across their niche (air, water) (Lennox 2005). Notice that this sort of conclusion is not far afield from an account of homology found in contemporary philosophy of biology:

behavioral homologies and homologies of function in anatomy can form [an] independent level of homology, with the anatomical structures that support function being transformed over time whilst the behavioral character or the functional character (e.g. the biomechanical profile of a movement) remains the same. (Griffiths 2006)

In other words, despite the species-specific anatomy of wings and fins that continued to diverge from the appendage of a common ancestor, aspects of their use in nicherelative locomotion were conserved.

It is notable that homologies of physiology and behavior play a crucial role in biological theorizing from Aristotle to the present, even as Aristotelian theory and natural selection differ fundamentally in their characterizations of speciation. With respect to our overarching point, if-in both the ancient and modern worlds-plants are initially regarded as non-perceiving and non-acting, then they are excluded prematurely from the process of inquiry by which discontinuous analogies or behavioral/functional homologies can establish a basic equality of kinds (e.g. fish alongside birds). We further consider this issue in the next section. 


\section{Stay planted or go loco: selective pressure on locomotive capacity}

In an increasingly oft-cited passage, Darwin (1875) observed in The Movements and Habits of Climbing Plants that:

It has often been vaguely asserted that plants are distinguished from animals by not having the power of movement. It should rather be said that plants acquire and display this power only when it is of some advantage to them; this being of comparatively rare occurrence, as they are affixed to the ground, and food is brought to them by the air and rain. (Darwin 1875, p. 206)

From the perspective of ecological-evolutionary models, apart from questions of descent and similarity, it must be asked, why is animal locomotion stably selected for? A straightforward answer is that animals rely on locomotion to find fuel in their niche, transform their niche, avoid harm, and secure their reproduction. Put differently, the sensory and action capacities of animals facilitate their adaptive behavior, matching sessile plants in this respect. While parallel molecular and electrophysiological processes underpin organismic function in both, plants simply have a different set of means to find fuel in their niche, transform their niche, avoid harm, and secure their reproduction. For instance, without untethered locomotion to forage for distal food, plants use directed growth to traverse spatial distances, facilitating how food is brought to them for autotrophic organic synthesis (Trewavas 2002).

When the natural behaviors of sessile plants and locomoting animals are understood as emergent from capacities shaped by basic adaptive pressures, it undermines the case that only animal capacities should be designated as cognitive. As we expand on below, varieties of both plants and animals anticipate and act on their environments on multiple nested timescales, while responding to environmental contingencies. Both indicate (bidirectional) niche adaptation, ranging from molecular biology to physiology to behavioral dynamics. In so far as a subset of these processes can be modelled as perception, action, memory, and learning, it is unclear what, if anything, is missing for at least some plants to count as cognizers.

Note that the morphological differences that underpin parallel adaptive process roles are present even between most animal species, as we saw above with bird wings and fish fins being implicated in locomotion (irrespective of their common ancestry). For a more illustrative example at this point in our argument, consider that some animals have gills and some have lungs, and that generally, these morphological structures and their constitutive low-level mechanisms are implicated in the environmental exchange of nutrients and waste, i.e. respiration. Moreover, the process of respiration is governed by electromechanical and electrochemical coordination. Notice, however, that this is true not only of gills and lungs, but also of leaves and roots. Plants adaptively alter aspects of their positioning pertinent to respiration via a network of intercellular interactions (Simons 1992). ${ }^{6}$

\footnotetext{
${ }^{6}$ It is not disputed that there are specific biophysical/physiological distinctions between animal and plant respiration (see Taiz and Zeiger 2010).
} 
The further significance of this example over and above the previous wing-fin locomotion example is that the respiratory process parallels between gills and lungs suggests (misleadingly) that these morphological differences are more similar to one another-in virtue of them belonging to animals - than either of them are to the morphology that underpins a parallel respiratory process in plants. This issue turns up when Boyle (2017) states that ("arguably") the difference between (e.g.) echolocating and non-echolocating animals is not a transformative fundamental difference, in contrast to equivalent differences between animals and plants (pp. 115-116). But, if equally complex processes of environmental sensing in some animals and some plants can be modelled as physiological and behavioral homologues, the similarities between them should have greater salience than the contingent divergences in implementation. As Godfrey-Smith (2017) emphasizes, gradations of cognitive complexity in homologous sensing, evaluating, and behavior can be found everywhere, as can landmark leaps: "sensing itself is ubiquitous; it is seen in unicellular organisms and plants as well as animals"-while even within the narrow arena of sensing by animal eyes, one can make various arguments for transformatively fundamental distinctions, such as low versus high resolution (p. 221).

\section{Lumbering under the yoke}

The respiration example above builds on the earlier quote from Griffiths (2006) on homologies of function in anatomy, and connects it to another:

The wing of a European house sparrow is homologous to the wing of a flamingo - both are avian wings. The avian wing is homologous to the forelimb of a lizard - both are tetrapod forelimbs. The tetrapod forelimb is homologous to the pectoral fin of a sarcopterygian fish - both are instances of the anterior paired appendages of Sarcopterygii. None of these relationships is a matter of degree - the avian wing is not more or less a homologue of the pectoral fin any more than the class Aves is more or less part of the Sarcopterygii or a sparrow more or less a bird. (Griffiths 2006, emphasis added)

We must emphasize again that we are using a less restrictive sense of homology than described above, but the point regarding all-or-nothing similarity remains. Returning to Aristotle's method of discontinuous analogies across sub-divisions, to underscore our emphasis, we note that a premature exclusion of plants from an inquiry into the processes and mechanisms of respiratory regulation-simply because plants are not thought to 'really' breathe - thereby establishes an equality between (e.g.) animal gill and lung, while plants are (unjustifiably) relegated to the lower ranks.

That something such as respiration is not exclusive to animals may appear to have minor significance. The critical point, however, is that whether such a capacity extends beyond animals is far from being a 'pure' empirical matter. For this reason, the a priori boundaries of any comparative approach to organisms gains crucial relevance when considering what have traditionally been regarded as mind-involving 
processes such as decision-making, problem-solving, joint action, and more (Keijzer 2019). These processes relate directly to more general capacities and attributes such as cognition and agency, both of which are bound up with ancient notions of self-motion (Gill 1994). Since Aristotle, there has been almost no subsidence in the historical tendency to deem plants as lacking in these respects.

To be clear, we do not impute high-level functions to morphological attributes. Rather, the (broadly speaking) comparative biology approach we adopt instead looks at morphological features as implementing mechanisms that play a role in low-level physiological processes. From the interoperation of lower levels, high-level processes emerge with observable functional roles in adaptive context (e.g. gills, lungs, leaves and roots are integral to the set of mechanisms implicated in respiratory processes that subserve niche-relative organism homeostasis). Thus, for instance, the cellular specializations of plants provide an alternative set of constraints on forms of cognition equivalent to those of animals (Calvo et al. 2017; Calvo and Trewavas 2020).

Building on and aligning with our earlier consideration of modelling general biological, adaptive, cognitive fundamentals not limited to animals (i-iii), we can now point to a corresponding multi-level organization (right-hand column) that could be reflected in generalized biological models of emergent cognitive processes (perception, memory, etc.):

General fundamentals

(i) An organism-niche boundary (even if ultimately transitory over longer timescales),

(ii) A set of organismic mechanisms implicated in processes for niche-perceiving and niche-actingupon that subserve gaining fuel and avoiding harm (even if ultimately transitory in development), and

(iii) Mediation of the processes in (ii) by endogenous electrical activity.
Organizational fundamentals

(i') A body-environment interface,

(ii') Cellular level activity (with endogenous correspondence to environmental and bodily states), and

(iii') Further activity involving coordinated populations of cells (or subcellular entities).

These 'levels' (right-hand column) affect each other (vertically) in both directions, with different degrees of complexity across species. However, such cognitive complexity does not simply increase linearly from plants to animals as convention tends to suggest-some instances of plant complexity exceed some instances of animal complexity.

Simpler animals and plants (and beyond) exhibit shallower nesting of spatiotemporally situated behavior, with environmental responsiveness unfolding over short time scales and close spatial range. As organismic complexity increases, so too does the number of nested spatiotemporal levels of behavior (Corcoran et al. 2020; Linson et al. 2018; Sims 2019; see also Calvo et al. 2020). In other words, such complexity in cognitive systems brings greater integration of increasingly longerterm, wider-range goals, arguably in order to meet their own increased (adaptive) demands, to survive and thrive. Sufficient cognitive complexity makes possible (but does not guarantee) certain transformative capacities, such as the capacity to 
re-evaluate a prospective decision and make an alternative decision, which may not extend beyond humans. But current models of cognition and available evidence do not reflect any such transformatively fundamental difference between (all) plants and animals.

\section{Getting nervous: the electrophysiology of plants}

In this section, we consider the convergence of cognitive models and evidence that contextualizes the superficially transformative difference between the brains found in animals but absent in plants. There is no question that brains are a morphologically localized development involved in coordinating coherent behavior. The question, however, is whether the coordination of coherent behavior with and without such a morphological localization can be biologically modelled in a similar manner. That is, setting aside universal formal abstractions such as dynamical systems models, can we understand the plant/animal analogy in terms of the emergence of cognitive behavior from physiology?

According to Darwin (1875), a number of behavioral and cognitive "animal features" were shared by plants, specifically, Dionea muscipula (the Venus flytrap) and Mimosa pudica (the 'sensitive' plant). ${ }^{7}$ This perspective on plants was not merely a metaphor, but rather, it informed his concrete elaboration of a 'root-brain' (Baluška et al. 2009). As Darwin saw it, an intriguing parallel could be drawn between plant roots and the brains of "lower" animals. Another oft-cited passage, from his penultimate book, The power of movement in plants (Darwin and Darwin 1880), states that:

It is hardly an exaggeration to say that the tip of the radicle thus endowed [with sensitivity] and having the power of directing the movements of the adjoining parts, acts like the brain of one of the lower animals; the brain being seated within the anterior end of the body, receiving impressions from the senseorgans, and directing the several movements. (Darwin and Darwin 1880), p. 573

The 'root-brain' concept took on broader significance in the context of a wider scientific inquiry that linked animal neurophysiology and plants, beginning around the turn of the last century - and which had a lasting impact, despite being overlooked for interim periods (Williams 1976).

Darwin hypothesized that electrical impulses could underlie fast responses in carnivorous plants, but he lacked the experimental toolkit to settle the matter. In the Royal Society, Darwin shared his insights with Sir John Burdon-Sanderson, a circumstantially ideal combination of medical doctor, botanist, and physiologist, who held successive professorships at UCL and Oxford. Their London meetings led to a

\footnotetext{
7 It is uncertain, but possible, that Darwin read the work of John Ray's contemporary, Nehemiah Grew. Grew seems to anticipate Darwin, with an implicit nod to Theophrastus, when he speaks of "the Sensible Natures of Vegetables, and of their more Recluse Faculties and Powers" in his 1672 Royal Society lecture, "An Idea of a Philosophical History of Plants", cited in Wilkins (2009).
} 
series of electrophysiological studies of plants, specifically, on their nervelike action potentials and related phenomena (Burdon-Sanderson 1873, 1877, 1882, 1888). The initial published findings on Dionaea electrophysiology set off a wave of subsequent research on 'animal-like' plant physiology and corresponding adaptive behavior, during which action potentials were measured in other plant species.

J.C. Bose continued biophysical and electrophysiological research on Mimosa and other plants (Bose 1907, 1913, 1926, 1928). As he observed in The Nervous Mechanism of Plants (Bose 1926), we cannot but acknowledge the "nervous character of the impulse transmitted to a distance" in plants. While Bose came to such conclusions decades before most others, subsequent research has borne out many of his once controversial claims (Shepherd 2005). ${ }^{8}$ Notably, Bose showed that plants have a coherent network of electrically excitable tissues that play a similar role to that of animal nervous systems. ${ }^{9}$

\section{Getting excited}

Echoing Darwin's claim about the analogue between plants and 'lower animals', contemporary investigations into plant electrophysiology have confirmed that "while most plants have little need of a nervous system as sophisticated as that of higher animals, at least some of them have a system comparable with that of the lower forms of animal life" (Goldsworthy 1983, p. 648). Specifically,

plants which show rapid movements in response to action potentials have arisen independently at many diverse points in evolution, ranging from the insectivorous plants of the Droseraceae, through Mimosa in the Leguminosae to the motile stamens of the barberry. These plants initiate their action potentials in response to touch ... All that is needed is for certain cells of the plant to be hypersensitive so that permeability to ions is increased by relatively minor mechanical deformation. Such cells occur just below the tentacle head in Drosera and at the base of the trigger hairs in Dionaea. They respond to mechanical stress as if they had been injured. They first become depolarized, generating the so-called receptor potential which triggers action potentials which propagate through the neighboring cells to the motor regions. (Goldsworthy 1983, p. 647)

The conclusion of this description of Dionaea is referring to the fact that upon the first disturbance of a mechanoreceptive 'trigger hair', as when a fly has landed on it, a relatively slow-moving action potential spreads over the trap, without leading to any visible movement. If a second stimulation occurs within approximately $30 \mathrm{~s}$,

\footnotetext{
${ }^{8}$ Even in his own time, he describes in the preface to The Motor Mechanism of Plants (Bose 1928) how scientific incredulity toward his work subsided once his instrument calibrations were validated by the Fellows of the Royal Society, his results were replicated at the Physiological Institute of the University of Vienna, and so on.

9 See De Loof (2016) for grounded speculation on what he terms the 'electrome' (analogous to genome), to describe "the electrical dimension of biological systems".
} 
it sets off a fast-moving action potential that leads to the rapid shutting of the trap (Hedrich and Neher 2018; Trebacz et al. 2006). Accidental closures are thereby reduced, which saves on energetically costly resetting, as actual prey typically causes multiple stimulations within the allotted time. This reflects a biological basis for perceptual discrimination that can be modelled in the same way as far more complex perceptual discrimination by humans, using (Bayesian) decision theory (e.g. Parr et al. 2019).

It was not until the turn of the last century that it was established in multiple independent laboratories that some plants were "equipped with various mechanoreceptors exceeding the sensitivity of a human finger" (Stahlberg 2006). One can ponder what might have been if Aristotle had enjoyed the benefits of modern technology and experimental data, in light of the fact that he believed mechanoreceptors were present in animals but absent in plants. As Freeland (1992) notes, Aristotle refers to a "special sort of 'mean'" that animals possess but plants lack. This sense of 'mean' describes a biological substrate that gauges the degree of environmental impact, for parameters such as pressure. She explains that this "would make more sense to us if we redescribed it as the claim that animal bodies include neural cells. For the sense of touch, these cells today are designated "mechanoreceptors"' (Freeland 1992).

It would be fair to say that brains remain more decisive than locomotion for distinguishing animals from plants in most contemporary cognitive research programs. Yet, brains are a morphological feature whose functional substrate is primarily understood in electrochemical terms. Thus, it is unproblematic to note that some aspects of brainbound phenomena may be mirrored in less centralized morphological features. In this light, it is notable that there is great diversity in plant electrical events, with some appearing when evoked and others spontaneously, displaying a range of fluctuation profiles that include self-propagating and localized activity (Pickard 1973). Together with other physiological mechanisms such as chemical coordination, plants are undoubtedly complex systems amenable to models of emergent behavioral dynamics (Volkov 2012). On this basis, it is increasingly argued that some plants may even be equipped to actively prioritize competing demands (Calvo et al. 2017; Züst and Agrawal 2017).

In higher plants (i.e. more recent species), organism-wide action-perception loops are coordinated in the glomerulus, a structure of richly interconnected phloem bundles (Behnke 1990). The glomerulus permits plants to sample and integrate a number of biotic and abiotic parameters in real time (Trewavas 2002). A coordinated bioelectrical network is effectively comprised of membranes of plant cells along the vascular system, which stretches throughout the plant body in the form of vascular bundles of phloem, xylem and cambium (Fromm and Lautner 2006). By measuring the overall electrical excitability of the cellular pathways connecting plant receptor and effector sites (Trebacz et al. 2006), a common metric can be established with animal innervation. Specifically, the former can mirror the connectivity in animals that links graded potentials in peripheral nerves and trains of action potentials in the central nervous system.

In sum, the cognitive process-supporting machinery most commonly associated with-and typically uniquely attributed to-animals, was identified in plants, not only in the ancient world by Parmenides and Theophrastus, but also by experimental 
science from the early twentieth century to the present. Such empirical findings on the complex bioelectrical networks that inhere in plants, and can be shown to facilitate aspects of cognitive behavior, support the argument for counting plants as straightforwardly cognitive (Baluška and Mancuso 2013; Segundo-Ortin and Calvo 2019). We avoid the anthropomorphism worry of Taiz et al. (2019) by relating cognition to whole-organism physiological coherence for self and niche response and modulation, which requires neither an animal brain nor a zoocentric classical information processing scheme. Moreover, the role of modelling we emphasize can contextualize animal-specific neurochemical interactions as implementations of cross-kingdom homologues, building on our previous examples of respiration and long-term potentiation. Is this approach too permissive? The next section resists this charge by further underscoring the complexity entailed even by 'simple' plant cognition.

\section{The agent is a plant: active botanical behavior}

Many potential candidates for adjudicating the cognitive boundary between plants and animals fall short in the face of mounting scientific evidence for a common model. One such candidate would be social cognition, which, when transformed by language, takes on a specific character in humans. Language-based social cognition indeed marks a difference in kind between human social cognition and that of nonhuman animals. However, this need not point to an equivalent difference between non-human animals and plants.

At the very least, constitutive processes of social cognition such as self/non-self discrimination and kinship networks have been empirically identified in plants. Self/ non-self discrimination in plants is facilitated by integrated physiological coordination involving oscillatory dynamics (Gruntman and Novoplansky 2004). A separate mechanism, related to root chemical exhudates (secretions), subserves the ability for plants to discriminate species kin from non-kin 'strangers' (Biedrzycki and Bais 2010; Biedrzycki et al. 2010; Crepy and Casal 2015; Dudley and File 2007; Semchenko et al. 2014). Both mechanisms pertain to survival with respect to the allocation of and competition over (endogenous and exogenous) resources. This again emphasizes the entanglement of biological, cognitive, and adaptive behavior.

Another candidate might be cognition-involving defensive behavior. Above, we noted that even single-celled organisms have been shown to exhibit this with the cognitive components of perceptual discrimination and responsive action coordination. Plants are no different in this respect, but as with simpler organisms, the requisite intricacy for scientific inquiry has only recently become possible.

How might the present-day chasm between zoology and botany have shaped up if Aristotle had the benefit of current technologies and experimental data? As Freeland (1992) highlights:

About the lower end of the spectrum, for example, Aristotle maintains that the distinction between plant and animal is hard to draw. ... He uses two sorts of information about an animal's sensory capacities: first, anatomical obser- 
vations - as when he tries to resolve the status of certain doubtful creatures, the ascidians [sea squirts], which are rooted, 'but yet they have some fleshy substance and therefore probably are capable of sensation of a kind'; and secondly, behavioral evidence — as when he adds to his remarks about the ascidians that they discharge a residue, something plants are not known to do. (Freeland 1992)

Shortly before these passages, ${ }^{10}$ Aristotle notes of the Cephalopod ability to squirt ink that "Nature makes good use of this residue ... for the animal's defense and preservation" (Tipton 2013). Once again defying Aristotle's assumptions, it is now known, for instance, that plants respond in a specific manner to herbivore-associated molecular patterns such as salivary proteins that are sensed via leaves (e.g. from the mouth of a leaf-chewing insect) (Züst and Agrawal 2017). In response, plants release jasmonate and a range of downstream compounds that discourage further herbivory. In other words, in at least two consequential cases-root-mediated competitor interaction, and leaf-mediated predator interaction-plant anatomy supports sensation, and behavioral evidence indicates they 'discharge a residue' for their 'defense and preservation'.

Aristotle notwithstanding, these cases also make for interesting examples of niche construction (i.e. non-passive adaptation) in relation to biotic factors: plants actively displace other plants and animals from their microhabitat. Plants also engage in niche construction in relation to abiotic factors, such as light. In cyclical fashion, the plant's perceptually guided growth requires fuel and nutrients, while this very growth reshapes their niche to optimize the plant's fuel and nutrient acquisition.

\section{Rife with anticipation}

Moreover, the capacity of shoots and roots to navigate terrains where resources are patchily distributed - and whose distribution can change dramatically, as in the case of sunflecks-can be modelled as anticipatory behavior (Novoplansky 2016). Consider how plants relate to a fleeting patch of light in particularly shady habitats. With plants being reliant on light for fuel, they exhibit complex behavioral responses to time-dependent changes in the light regime. A mere sunfleck that rapidly shifts throughout the day can be life-critical to under-canopy species-a single fleck lasting a few minutes may contain up to $50 \%$ of the daily sunlight intake (Taiz and Zeiger 2010). Whether cast as light seeking, or as escape or avoidance responses to shade, these behaviors require tracking and extrapolating from historical trends in the amount and spectral quality of light (Gundel et al. 2014). This extrapolation facilitates the timely control of physical patterns of growth, as plants must grow and branch differentially, depending upon the prospects to acquire light.

As with animals, such anticipatory adaptive responses can be observed as emerging from the coordinated interoperation of low-level physiological mechanisms. Shade-avoidance in plants exploits the way light is reflected under canopy, as canopy

${ }^{10}$ PA 681 $25-35$ above; $679^{\mathrm{a}} 79-81$ hereafter. 
gaps excite photoreceptors that respond to differences in the electromagnetic spectrum (Franklin and Whitelam 2005). Whereas phytochromes are sensitive to changes in the ratio of red to far-red (R:FR) light, cryptochromes and phototropins absorb the blue (B) and UV-A part of the spectrum. Plants integrate these light cues over time, and coordinate across the root and shoot systems (Baluška et al. 2004; Trewavas 2014). Changes in the R:FR ratio can alter root allocation and the morphology of the root apparatus overall (Gundel et al. 2014). The behavioral repertoire of plants thus emerges from a richly complex interplay between photosensory and other perceptual subsystems (Bastien et al. 2015). This interplay leads to long-distance pathway activation and downstream (e.g. hydraulic and chemical) responses (Gilroy et al. 2016; Huber and Bauerle 2016).

We have characterized a particular pattern of plant response to shade escape or avoidance that could be classed as an anticipatory defensive behavior. Even if this were considered a grey area, it is clear that multiple aspects of growth and defense form part of the plant behavioral repertoire. In this regard, it is notable that among plant scientists, "an emerging consensus ... identifies negative associations between growth and defense not as the direct result of allocation costs, but rather as prioritization of one process over another" (Züst and Agrawal 2017). Such an account supports biologically grounded decision-theoretic models in which plants select an action from a range of growth and defensive alternatives.

As Calvo and Baluška (2015) point out, one of the commonalities among specific plants and animals is photosensory-induced acute stress escape behavior. Empirical studies of photophobia in plant roots demonstrate its behavioral robustness (Yokawa et al. 2011, 2014). Properly defensive behavior against predators differs in key respects from other behavior that amounts to seeking hospitable conditions, such as avoiding the terrestrial surface to extend root growth underground. But this does not preclude plausibly hypothesized deep homologies between plant and animal behavior. Both cases can be modelled as an aversive behavior emergent from a patterned interplay of perception and action.

Such patterned interplay can be cast as an inducible defense. Huey et al. (2002) predict stronger inducible defense in plants as compared to animals, by appealing explicitly to the sessile/mobile contrast (plants are unable to 'run away'). We would counter, however, that strength in this sense is not univocally defined across response modalities. Thus, the combined respective defensive repertoires of plants and animals should be considered on par with one another, in so far as they have been selected for adequacy to survive and thrive.

On the animal side, Kane et al. (2013) suggest that the reason Drosophila larvae cease moving in abrupt darkness may relate to avoiding detection by a looming predator that casts its shadow over them. This appears to match the developmentally dependent variant of this response in adult houseflies, whose darkness-induced escape behavior is (aerial) flight (Holmqvist and Srinivasan 1991). These responses are consistent with the under-canopy plants' shade avoidance or escape behavior described above, as enduring shade induces acute stress. For underground maize roots, what amounts to the same model could be used to understand the relationship of physiology to emergent behavior, with only the poles of one parameter swapped. That is, a simple brightness vector captures the relevant photosensory apparatus for 
the maize roots' photophobia and the insects' darkness aversion. This comparison should be taken as an illustration of how a biologically grounded model of a cognitive phenomenon of interest-in this case, perceptual discrimination coupled with an appropriate behavioral response-could be modelled in a way that remains consistent across plant and animal evidence. ${ }^{11}$

\section{Conclusion}

It seems that the line drawn between plants and animals cannot be held to be the very same line dividing non-cognitive and cognitive kinds. If particular physiological features make cognition possible, one could assert that some animals have them, and no plants do-but then we are reduced to tautology, in that only animals can provide evidence for animal models of cognition. Alternatively, one could say that there is a general model of cognition, for which only animals provide evidence, and plants do not. But then one is faced with deciding at what (non-arbitrary) point all of the relevant capacities came into coherence to produce cognition, while maintaining that (e.g.) more ancient homologues of each feature are insufficient for cognition in their given organization. It seems that any principled way of drawing that boundary reflects pragmatic or aesthetic considerations, rather than locating a perspective-free carving of nature at its joints.

For example, the capacity of memory has been variously regarded as being a feature solely of mammalian brains, later contested by findings on insect brains, and now contested in part by non-brainbound notions of extended and distributed cognition. As we have pointed out, a similarly contested ground is underfoot for attributing memory to plants, alongside other cognitive capacities. It should therefore be taken as a given that scientific and philosophical normative shifts in models or conceptions of cognitive capacities play a key role in specifying what counts as cognition. This does not mean that the inquiry into cognition is 'just semantics', but rather, it means that we are at best only ever on the way to carving nature at its joints, but never arriving, due to the permanent prospect of revision.

The common trope of all observations being theory laden is especially highlighted by the notion that methodologically sound observations can be treated as evidence for a model. Theories of cognition effectively entail models, so care must be taken in the model definitions before judgments of exclusion by kind are made. If the concern is simply with morphological kinds, then many natural divisions may be relevant beyond having a brain or not, having a cortex or not, having compound eyes or not, and so on. But if the concern is with cognitive and non-cognitive kinds, we should not be so hasty in dismissing how coherently organized physiological networks of sensing, acting, memory, and learning within whole organisms provide evidence for models of cognition. We hope to have offered a non-zoocentric way of

\footnotetext{
11 For a generalized animal example of this kind of model that includes mammals and insects, and could be extended to plants, see Linson et al. (2020).
} 
locating cognition beyond animals, while indicating that the continued exclusion of plants from the cognitive club is unwarranted.

Acknowledgements An early version of this paper was presented to the University of Stirling, Department of Philosophy. The authors thank the audience for their feedback, with special thanks to Giacomo Melis, Mike Wheeler, and Alan Millar for extensive helpful discussions following the talk.

Funding Paco Calvo is funded by the Office of Naval Research Global (N62909-19-1-2015).

Open Access This article is licensed under a Creative Commons Attribution 4.0 International License, which permits use, sharing, adaptation, distribution and reproduction in any medium or format, as long as you give appropriate credit to the original author(s) and the source, provide a link to the Creative Commons licence, and indicate if changes were made. The images or other third party material in this article are included in the article's Creative Commons licence, unless indicated otherwise in a credit line to the material. If material is not included in the article's Creative Commons licence and your intended use is not permitted by statutory regulation or exceeds the permitted use, you will need to obtain permission directly from the copyright holder. To view a copy of this licence, visit http://creativecommons.org/licen ses/by/4.0/.

\section{References}

Adams F (2018) Cognition wars. Stud Hist Philos Sci Part A 68:20-30. https://doi.org/10.1016/j.shpsa .2017.11.007

Allen C (2017) On (not) defining cognition. Synthese 194:4233-4249. https://doi.org/10.1007/s1122 9-017-1454-4

Allen C, Bekoff M (1999) Species of mind: The philosophy and biology of cognitive ethology. A bradford book. MIT Press, Cambridge, MA

Baluška F, Levin M (2016) On having no head: cognition throughout biological systems. Front Psychol 7:902

Baluška F, Mancuso S (2009) Plants and animals: Convergent evolution in action? In: Baluška F (ed) Plant-environment interactions: from sensory plant biology to active plant behavior. Springer, Berlin, pp 285-301. https://doi.org/10.1007/978-3-540-89230-4_15

Baluška F, Mancuso S (2013) Microorganism and filamentous fungi drive evolution of plant synapses. Front Cell Infect Microbiol 3:44

Baluška F, Reber A (2019) Sentience and consciousness in single cells: how the first minds emerged in unicellular species. BioEssays 41:1800229. https://doi.org/10.1002/bies.201800229

Baluška F, Mancuso S, Volkmann D, Barlow P (2004) Root apices as plant command centres: the unique 'brain-like' status of the root apex transition zone. Biologia 59:7-19

Baluška F, Mancuso S, Volkmann D, Barlow P (2009) The 'root-brain' hypothesis of Charles and Francis Darwin: revival after more than 125 years. Plant Signal Behav 4:1121-1127

Bastien R, Bohr T, Moulia B, Douady S (2013) Unifying model of shoot gravitropism reveals proprioception as a central feature of posture control in plants. Proc Natl Acad Sci 110:755. https://doi. org/10.1073/pnas.1214301109

Bastien R, Douady S, Moulia B (2015) A unified model of shoot tropism in plants: photo-, gravi-and propio-ception. PLoS Comput Biol 11:e1004037

Behnke HD (1990) Sieve elements in internodal and nodal anastomoses of the monocotyledon liana dioscorea. In: Behnke HD, Sjolund RD (eds) Sieve elements: comparative structure, induction and development. Springer, Berlin, pp 161-178

Biedrzycki ML, Bais HP (2010) Kin recognition: another biological function for root secretions. Plant Signal Behav 5:401-402. https://doi.org/10.4161/psb.5.4.10795

Biedrzycki ML, Jilany TA, Dudley SA, Bais HP (2010) Root exudates mediate kin recognition in plants. Commun Integr Biol 3:28-35. https://doi.org/10.4161/cib.3.1.10118

Bird A (2018) The metaphysics of natural kinds. Synthese 195:1397-1426. https://doi.org/10.1007/s1122 9-015-0833-y 
Bose JC (1907) Comparative electro-physiology, a physico-physiological study. Longmans, Green, and Co., London

Bose JC (1913) Researches on irritability of plants. Longmans, Green, and Co., London

Bose JC (1926) The nervous mechanism of plants. Longmans, Green, and Co., London

Bose JC (1928) The motor mechanism of plants. Longmans, Green, and Co., London

Boyle M (2017) A different kind of mind? In: Andrews K, Beck J (eds) The Routledge handbook of philosophy of animal minds. Routledge, New York, pp 109-118

Bredlow LA (2011) Aristotle, theophrastus, and parmenides' theory of cognition (b 16). Apeiron 44:219-263

Burdon-Sanderson JS (1873) I. Note on the electrical phenomena which accompany irritation of the leaf of dionæa muscipula. Proc R Soc Lond 21:495-496

Burdon-Sanderson JS (1877) Note on the electrical disturbance which accompanies the excitation of the stigma of mimulus luteus. Nature 16:163-164. https://doi.org/10.1038/016163e0

Burdon-Sanderson JS (1882) I. On the electromotive properties of the leaf of dionæa in the excited and unexcited states. Philos Trans R Soc Lond 173:1-55

Burdon-Sanderson JS (1888) Xvi. On the electromotive properties of the leaf of dionæa in the excited and unexcited states.- -second paper. Philos Trans R Soc Lond (B) 179:417-449

Burge T (2010) Origins of objectivity. Oxford University Press, New York

Calvo P (2017) What is it like to be a plant? J Conscious Stud 24:205-227

Calvo P (2018) Caterpillar/basil-plant tandems animal sentience: an interdisciplinary. J Anim Feel $1: 16$

Calvo P, Baluška F (2015) Conditions for minimal intelligence across eukaryota: a cognitive science perspective. Front Psychol 6:1329

Calvo P, Friston K (2017) Predicting green: really radical (plant) predictive processing. J R Soc Interface 14:20170096. https://doi.org/10.1098/rsif.2017.0096

Calvo P, Trewavas A (2020) Cognition and intelligence of green plants: information for animal scientists. Biochem Biophys Res Commun. https://doi.org/10.1016/j.bbrc.2020.07.139

Calvo Garzón P, Keijzer F (2009) Cognition in plants. In: Baluška F (ed) Plant-environment interactions. Springer, Berlin, pp 247-266

Calvo Garzón P, Keijzer F (2011) Plants: adaptive behavior, root-brains, and minimal cognition. Adapt Behav 19:155-171

Calvo P, Sahi VP, Trewavas A (2017) Are plants sentient? Plant Cell Environ 40:2858-2869

Calvo P, Gagliano M, Souza GM, Trewavas A (2020) Plants are intelligent, here's how. Ann Bot 125:11-28

Chang H (2010) The hidden history of phlogiston. HYLE Int J Philos Chem 16:47-79

Chemero A (2009) Radical embodied cognitive science. MIT Press, Cambridge, MA

Clark A (1997) Being there: putting brain, body, and world together again. A bradford book. Bradford Book, Cambridge, MA

Corcoran AW, Pezzulo G, Hohwy J (2020) From allostatic agents to counterfactual cognisers: active inference, biological regulation, and the origins of cognition. Biol Philos. https://doi. org/10.1007/s10539-020-09746-2

Crepy MA, Casal JJ (2015) Photoreceptor-mediated kin recognition in plants. New Phytol 205:329338. https://doi.org/10.1111/nph.13040

Darwin C (1875) The movements and habits of climbing plants. John Murray, London

Darwin C, Darwin F (1880) The power of movements in plants. Appleton and Company, New York

De Loof A (2016) The cell's self-generated "electrome": the biophysical essence of the immaterial dimension of life? Commun Integr Biol 9:e1197446

Dennett D (1976) Conditions of personhood. In: Rorty AO (ed) The identities of persons. University of California Press, Berkeley, CA, pp 175-196

Dennett D (2009) Intentional systems theory. In: McLaughlin B, Beckermann A, Walte S (eds) The Oxford handbook of philosophy of mind. OUP Oxford, Oxford, pp 339-350

Dexter JP, Prabakaran S, Gunawardena J (2019) A complex hierarchy of avoidance behaviors in a single-cell eukaryote. Curr Biol 29:4323-4329

Dudley SA, File AL (2007) Kin recognition in an annual plant. Biol Let 3:435-438. https://doi. org/10.1098/rsbl.2007.0232

Ereshefsky M (2007a) Psychological categories as homologies: lessons from ethology. Biol Philos 22:659-674. https://doi.org/10.1007/s10539-007-9091-9 
Ereshefsky M (2007b) Species, taxonomy, and systematics. In: Matthen M, Stephens C (eds) Philosophy of biology. North-Holland, Amsterdam, pp 403-427. https://doi.org/10.1016/b978-04445 1543-8/50020-4

Ereshefsky M, Reydon TAC (2015) Scientific kinds. Philos Stud 172:969-986. https://doi. org/10.1007/s11098-014-0301-4

Finger S, Piccolino M (2011) The shocking history of electric fishes: from ancient epochs to the birth of modern neurophysiology. Oxford University Press, Oxford

Franklin KA, Whitelam GC (2005) Phytochromes and shade-avoidance responses in plants. Ann Bot 96:169-175

Freeland C (1992) Aristotle on the sense of touch. In: Nussbaum MC, Rorty AO (eds) Essays on Aristotle's de anima. Oxford University Press, Oxford, pp 227-248

Fromm J, Lautner S (2006) Characteristics and functions of phloem-transmitted electrical signals in higher plants. In: Baluška F, Mancuso S, Volkmann D (eds) Communication in plants: neuronal aspects of plant life. Springer, Berlin, pp 321-332. https://doi.org/10.1007/978-3-540-28516-8_22

Gill ML (1994) Aristotle on self-motion. In: Gill ML, Lennox JG (eds) Self-motion: from Aristotle to Newton. Princeton University Press, Princeton, NJ, pp 15-34

Gilroy S, Białasek M, Suzuki N, Górecka M, Devireddy AR, Karpiński S, Mittler R (2016) Ros, calcium, and electric signals: key mediators of rapid systemic signaling in plants. Plant Physiol 171:1606-1615

Godfrey-Smith P (1994) Spencer and Dewey on life and mind. Proc Artif Life IV 1994:80-89

Godfrey-Smith P (2017) The evolution of consciousness in phylogenetic context. In: Andrews K, Beck J (eds) The Routledge handbook of animals minds. Routledge, New York

Goldsworthy A (1983) The evolution of plant action potentials. J Theor Biol 103:645-648

Gorshkova T, Chernova T, Mokshina N, Ageeva M, Mikshina P (2018) Plant 'muscles': fibers with a tertiary cell wall. New Phytol 218:66-72. https://doi.org/10.1111/nph.14997

Green J, Hazard E (1809) An epitome of electricity \& galvanism. Jane Aitken, No. 71, North Third Street, Philadelphia

Griffiths PE (1994) Cladistic classification and functional explanation. Philos Sci 61:206-227

Griffiths PE (2006) Function, homology, and character individuation. Philos Sci 73:1-25

Griffiths PE (2007) The phenomena of homology. Biol Philos 22:643-658. https://doi.org/10.1007/s1053 9-007-9090-X

Gruntman M, Novoplansky A (2004) Physiologically mediated self/non-self discrimination in roots. Proc Natl Acad Sci USA 101:3863. https://doi.org/10.1073/pnas.0306604101

Gundel PE, Pierik R, Mommer L, Ballaré CL (2014) Competing neighbors: light perception and root function. Oecologia 176:1-10

Hall BK (2003) Descent with modification: the unity underlying homology and homoplasy as seen through an analysis of development and evolution. Biol Rev 78:409-433. https://doi.org/10.1017/ S1464793102006097

Hedrich R, Neher E (2018) Venus flytrap: how an excitable, carnivorous plant works. Trends Plant Sci 23:220-234. https://doi.org/10.1016/j.tplants.2017.12.004

Holmqvist MH, Srinivasan MV (1991) A visually evoked escape response of the housefly. J Comp Physiol A 169:451-459. https://doi.org/10.1007/BF00197657

Huber AE, Bauerle TL (2016) Long-distance plant signaling pathways in response to multiple stressors: the gap in knowledge. J Exp Bot 67:2063-2079

Huey RB et al (2002) Plants versus animals: do they deal with stress in different ways? Integr Comp Biol 42:415-423

Hughes JD (1985) Theophrastus as ecologist. Environ Rev: ER 9:297-306. https://doi.org/10.2307/39844 60

Kane EA et al (2013) Sensorimotor structure of drosophila larva phototaxis. Proc Natl Acad Sci 110:E3868-E3877

Kaplan DM (2017) A bridge too far? Inference and extrapolation from model organisms in neuroscience. In: Andrews K, Beck J (eds) The Routledge handbook of philosophy of animal minds. Routledge, Abingdon, pp 448-457

Karban R (2008) Plant behaviour and communication. Ecol Lett 11:727-739

Keijzer F (2017) Evolutionary convergence and biologically embodied cognition. Interface Focus 7:20160123. https://doi.org/10.1098/rsfs.2016.0123

Keijzer F (2019) Describing atypical instances of intelligence: the case of habituation. BioEssays: News Rev Mol Cell Dev Biol 41:e1900079-e1900079 
Keller T, Damude HG, Werner D, Doerner P, Dixon RA, Lamb C (1998) A plant homolog of the neutrophil nadph oxidase gp91phox subunit gene encodes a plasma membrane protein with $\mathrm{Ca}^{2+}$ binding motifs. Plant Cell 10:255-266

Kirchhoff M, Parr T, Palacios E, Friston K, Kiverstein J (2018) The markov blankets of life: autonomy, active inference and the free energy principle. J R Soc Interface 15:20170792. https://doi. org/10.1098/rsif.2017.0792

Knuuttila T (2011) Modelling and representing: an artefactual approach to model-based representation. Stud Hist Philos Sci Part A 42:262-271. https://doi.org/10.1016/j.shpsa.2010.11.034

Kunita I, Yamaguchi T, Tero A, Akiyama M, Kuroda S, Nakagaki T (2016) A ciliate memorizes the geometry of a swimming arena. J R Soc Interface 13:20160155. https://doi.org/10.1098/ rsif.2016.0155

Kutschera U, Briggs WR (2009) From Charles Darwin's botanical country-house studies to modern plant biology. Plant Biology 11:785-795

Lakoff G, Johnson M (1999) Philosophy in the flesh. Basic Books, New York, NY

Lankester ER (1870) Ii.- on the use of the term homology in modern zoology, and the distinction between homogenetic and homoplastic agreements. Ann Mag Nat Hist 6:34-43. https://doi. org/10.1080/00222937008696201

Lennox JG (2005) Getting a science going: Aristotle on entry level kinds. In: Wolters G, Carrier M (eds) Homo Sapiens und Homo Faber: Festschrift Mittelstrass. Walter de Gruyter, Berlin, pp 87-100

Lennox JG (2009) Form, essence, and explanation in Aristotle's biology. In: Anagnostopoulos G (ed) A companion to aristotle. Blackwell, Oxford, pp 348-367. https://doi.org/10.1002/9781444305661. ch22

Leovy C (2001) Weather and climate on mars. Nature 412:245-249. https://doi.org/10.1038/35084192

Linson A, Clark A, Ramamoorthy S, Friston K (2018) The active inference approach to ecological perception: general information dynamics for natural and artificial embodied cognition. Front Robot AI. https://doi.org/10.3389/frobt.2018.00021

Linson A, Parr T, Friston KJ (2020) Active inference, stressors, and psychological trauma: a neuroethological model of (mal)adaptive explore-exploit dynamics in ecological context. Behav Brain Res 380:112421. https://doi.org/10.1016/j.bbr.2019.112421

Loux MJ (1992) Aristotle and parmenides: an interpretation of physics a8. Proc Boston Area Colloq Anc Philos 8:281-319. https://doi.org/10.1163/2213441792X00177

Marder M (2012) Plant intentionality and the phenomenological framework of plant intelligence. Plant Signal Behav 7:1365-1372

Margulis L (2001) The conscious cell. Ann N Y Acad Sci 929:55-70. https://doi. org/10.1111/j.1749-6632.2001.tb05707.x

Michmizos D, Hilioti Z (2019) A roadmap towards a functional paradigm for learning \& memory in plants. J Plant Physiol 232:209-215. https://doi.org/10.1016/j.jplph.2018.11.002

Nersessian NJ (1984) Aether/or: the creation of scientific concepts. Stud Hist Philos Sci Part A 15:175-212

Nicholson DJ, Dupré J (eds) (2018) Everything flows: towards a processual philosophy of biology. Oxford University Press. https://doi.org/10.26530/OAPEN_1000196

Novoplansky A (2016) Future perception in plants. In: Nadin M (ed) Anticipation across disciplines. Springer, Cham, pp 57-70

Parr T, Mirza MB, Cagnan H, Friston KJ (2019) Dynamic causal modelling of active vision. J Neurosci 39:6265. https://doi.org/10.1523/JNEUROSCI.2459-18.2019

Pickard BG (1973) Action potentials in higher plants. Bot Rev 39:172-201

Ramstead MJD, Badcock PB, Friston KJ (2018) Answering schrödinger's question: a free-energy formulation. Phys Life Rev 24:1-16. https://doi.org/10.1016/j.plrev.2017.09.001

Reber AS (2016) Caterpillars, consciousness and the origins of mind animal sentience: an interdisciplinary. J Anim Feel 1:1

Scotland RW (2010) Deep homology: a view from systematics. BioEssays 32:438-449. https://doi. org/10.1002/bies.200900175

Segundo-Ortin M, Calvo P (2019) Are plants cognitive? A reply to adams. Stud Hist Philos Sci Part A 73:64-71. https://doi.org/10.1016/j.shpsa.2018.12.001

Semchenko M, Saar S, Lepik A (2014) Plant root exudates mediate neighbour recognition and trigger complex behavioural changes. New Phytol 204:631-637. https://doi.org/10.1111/nph.12930

Shepherd V (2005) From semi-conductors to the rhythms of sensitive plants: the research of JC Bose. Cell Mol Biol (Noisy-le-grand) 51:607-619. https://doi.org/10.1170/T670 
Simons P (1992) The action plant: movement and nervous behaviour in plants. Blackwell, Oxford

Sims M (2019) Minimal perception: responding to the challenges of perceptual constancy and veridicality with plants. Philos Psychol 32:1024-1048. https://doi.org/10.1080/09515089.2019.1646898

Sloman A (1988) Why philosophers should be designers. Behav Brain Sci 11:529-530

Stahlberg R (2006) Historical overview on plant neurobiology. Plant Signal Behav 1:6-8. https://doi. org/10.4161/psb.1.1.2278

Stamos DN (2002) Species, languages, and the horizontal/vertical distinction. Biol Philos 17:171-198

Stein N (2018) Definition and the epistemology of natural kinds in aristotle. Metaphysics 1:33-51

Taiz L, Zeiger E (2010) Plant physiology, 5th edn. Sinauer Associates, Sunderland, MA

Taiz L et al (2019) Plants neither possess nor require consciousness. Trends Plant Sci 24:677-687

Thompson E (2007) Mind in life: biology, phenomenology, and the sciences of mind. Harvard University Press, Cambridge, MA

Tipton JA (2013) Philosophical biology in Aristotle's parts of animals. Studies in history and philosophy of science. Springer, Berlin

Trebacz K, Dziubinska H, Krol E (2006) Electrical signals in long-distance communication in plants. In: Baluška F, Mancuso S, Volkmann D (eds) Communication in plants: neuronal aspects of plant life. Springer, Berlin, pp 277-290. https://doi.org/10.1007/978-3-540-28516-8_19

Trewavas A (2002) Plant intelligence: mindless mastery. Nature 415:841. https://doi.org/10.1038/41584 $1 \mathrm{a}$

Trewavas A (2003) Aspects of plant intelligence. Ann Bot 92:1-20. https://doi.org/10.1093/aob/mcg101

Trewavas A (2014) Plant behaviour and intelligence. Oxford University Press, Oxford

Varela FJ, Thompson E, Rosch E (1991) The embodied mind: cognitive science and human experience. MIT Press, Cambridge, MA

Volkov AG (2012) Plant electrophysiology: Signaling and responses. Plant electrophysiology. Springer, Berlin

Weisberg M (2013) Simulation and similarity: Using models to understand the world. Oxford Studies in Philosophy of Science. OUP USA, New York

Wheeler M (1997) Cognition's coming home: the reunion of life and mind. In: Proceedings of the fourth European conference on artificial life, 1997. pp 10-1

Wheeler M (2005) Reconstructing the cognitive world: the next step. Bradford book. MIT Press, Cambridge, MA

Whittaker RH (1969) New concepts of kingdoms of organisms. Science 163:150. https://doi.org/10.1126/ science.163.3863.150

Wilkins JS (2009) Species: a history of the idea, vol 1. University of California Press, Berkeley, CA

Williams SE (1976) Comparative sensory physiology of the droseraceae-the evolution of a plant sensory system. Proc Am Philos Soc 120:187-204

Winsor MP (2003) Non-essentialist methods in pre-Darwinian taxonomy. Biol Philos 18:387-400

Yokawa K, Kagenishi T, Kawano T, Mancuso S, Baluška F (2011) Illumination of arabidopsis roots induces immediate burst of ROS production. Plant Signal Behav 6:1460-1464. https://doi. org/10.4161/psb.6.10.18165

Yokawa K, Fasano R, Kagenishi T, Baluška F (2014) Light as stress factor to plant roots — case of root halotropism. Front Plant Sci 5:718

Zachos FE (2016) Species concepts in biology: historical development, theoretical foundations and practical relevance. Springer, Berlin

Züst T, Agrawal AA (2017) Trade-offs between plant growth and defense against insect herbivory: an emerging mechanistic synthesis. Annu Rev Plant Biol 68:513-534

Publisher's Note Springer Nature remains neutral with regard to jurisdictional claims in published maps and institutional affiliations. 